\title{
Urbanismo y sociedades en tránsito La ciudad como representación de una crisis crónica
}

\author{
Urban development and societies in transit \\ The City as a representation of a chronic crisis
}

Rafael Ojeda ${ }^{1}$

\begin{abstract}
RESUMEN
El presente artículo, desde una revisión histórica y urbana, estudia las transformaciones experimentadas por la ciudad en los últimos cincuenta años, en los que los complejos urbanos han empezado a ser afectados por un constante proceso de aglomeración y una emergente y contradictoria tendencia hacia la desaglomeración urbana y social. Un proceso en el que suburbia es canibalizada por el crecimiento constante de las metrópolis, que al fagocitarlas, se van transformando en megalópolis expansivas, caóticas y desbordadas, desde tendencias enfrentadas, si evaluamos la situación de las ciudades de los centros del mundo frente a las ciudades de las periferias.
\end{abstract}

\section{Palabras clave}

Ciudad, urbanismo, arquitectura, paisajismo, fragmentación territorial, crisis urbana, hiperpoblación, gentrificación, ciudad moderna, ciudad posmoderna.

\begin{abstract}
This paper studied, from a historical and urban perspective, the transformations occurred in the cities in the last fifty years, in which a continuing process of agglomeration and an emerging and contradicting trend towards urban and social disagglomeration began to affect urban complexes. During this process, suburbia are cannibalized by the constant growth of metropolis, which are then transformed into expansive, chaotic and overwhelmed megalopolis, from counteracting trends, if we evaluate the situation of the world's central cities compared to the suburban cities.
\end{abstract}

\section{Keywords}

City, urban development, architecture, landscape architecture, territorial fragmentation, urban crisis, overpopulation, gentrification, modern city, postmodern city.

Hay en el espacio urbano, una noción de estructura, funcional en términos de eficacia y eficiencia, pero que, debido a los cambios que ha experimentado la ciudad en las últimas décadas, parece haber colapsado. Es decir, un proceso de racionalización vía el análisis de la relación individuo-sociedad, sustentada en las estructuras predeterminadas por el diseño urbano, con el fin de optimizar una distribución conveniente de los espacios privados y públicos, según su eficacia en términos de operatividad, tiempo y automatismo, que parecen haber quedado desfasadas. Por lo que trasciende la idea de que atravesamos un período de turbulencias marcado por una profunda crisis urbana, que nos ha llevado a considerar múltiples causas, como el centralismo que ha abigarrado demográfica, cultural $y$ socialmente a la ciudad, la hiperpoblación producida de las migraciones, los conflictos sociales y culturales producto del crecimiento caótico de las periferias metropolitanas, y

1 Investigador, escritor, ensayista. Ha publicado textos colectivos e individuales. Ha participado en diversos congresos y eventos nacionales e internacionales. Ha sido galardonado por sus investigaciones tanto en el Perú como en el extranjero. 
las fracturas o distancias sociales que han producido infranqueables brechas económicas entre los sectores pudientes y pobres de la ciudad, además de los agudizados procesos de insalubridad, inseguridad y hacinamiento, presentados como las causas concretas de la crisis urbana.

Sociológica y formalmente podemos definir la ciudad como espacio geográfico urbanizado, foco de poder político y eje de la vida económica, social y religiosa, pero como centro dinámico y lugar de las innovaciones tecnológicas, científicas y filosóficas. Por lo que, considerar a la ciudad como una entidad concreta sumida en un proceso de evolución constante, explica por qué estas, que surgieron para dar solución a los problemas específicos de la época en las que fueron concebidas, con el paso de los años y con los cambios económicos, sociales y territoriales, además del aumento de la densidad poblacional, ya no puedan responder a las novísimas exigencias de la vida económica y social contemporánea. Pues el crecimiento caótico de las periferias de las grandes urbes, producto de las múltiples oleadas migratorias, está planteando nuevos desafíos que las ciudades modernas no pueden resolver.

En este sentido, los continuos cambios de configuración, debido a la sobreextensión y la precarización de los espacios tradicionales de la ciudad y su incidencia en la autoconciencia poblacional, han hecho que proyectar un estudio que pretenda abarcar toda la complejidad urbana, nos remita a un esfuerzo interdisciplinario que procure copar todo el sistema de representaciones de la ciudad, a partir de conceptos provenientes de la arquitectura, el urbanismo, la sociología, la economía, la psicología social, la antropología urbana, además de otras ramas disciplinares sustentadas en las ciencias sociales.

\section{Arquitectura, urbanismo y ciencias sociales}

Un estudio de las estructuras de las metrópolis más importantes del mundo, separando este del factor demográfico, hace inevitable sectorizarlas en tres planos distintos $y$ complementarios: el del urbanismo, el de la arquitectura y el del paisajismo; disciplinas ineludibles que constituyen, debido a su carácter público, el foco de interés que debería tener todo habitante por su ciudad. Elemento que hace imposible no tener una impresión, aunque sea ingenua del espacio social y físico en el que se habita, una mirada crítica que implique un acercamiento racionalizado a las estructuras arquitectónicas de los edificios, al esquema de los parques y zonas libres o a los elementos formales del diseño urbano; es decir, el diseño combinado y racionalizado, en términos de operatividad y funcionamiento, de construcciones y espacios abiertos, de zonas públicas y privadas que, a pesar de tener antiguos referentes constructivos, debido a los cambios que ha venido experimentando la ciudad, obedecen más bien al ideal contemporáneo de habilitación y reconstrucción generalizada.

En este sentido, aunque los conceptos y límites entre campos disciplinares constructivos resultan ser un tanto maleables; son los arquitectos los que suelen diseñar habitaciones, casas o rascacielos, mientras las ciudades son planificadas por los urbanistas, quienes establecen la disposición, formas y distribución de los edificios, además del ordenamiento de los espacios públicos; en tanto, los espacios libres no intervenidos por la arquitectura ni diseñados por los urbanistas, son explorados y desarrollados por el paisajismo, que con sus aportes eminentemente plásticos, vía el planeamiento natural, ha logrado obras maestras de la jardinería, que podrían estar inscritas en el terreno del land art o arte térreo. Algo que se hace evidente, sobre todo si pensamos en Brasilia, ciudad modernista edificada de la nada para constituirse en la nueva capital de Brasil, y que hacia 1960, geopolíticamente reemplazará a Río de Janeiro como centro político para articular el plan de penetración brasileña hacia occidente.

Brasilia, una de las ciudades inspiradas por la Carta de Atenas [1943], de Le Corbusier y el CIAM, tendrá en la figura del brasileño Roberto Burle Marx al tercero en disputa. Un paisajista cuyos trabajos, tras una mirada aérea, podrían parecer extraídos de algunos óleos de Miró, con las sinuosidades y el color obedeciendo 
a la manipulación de flores, plantas, baldosas entre otros materiales ornamentales que han reforzado la pictoricidad de sus obras. Él será el diseñador de los jardines y parques de aquella ciudad planificada por el urbanista brasileño Lucio Costa, en sus trazados metropolitanos, ejes viales y monumentales, y por el también brasileño Oscar Niemeyer, responsable del planeamiento y edificación de sus principales estructuras arquitectónicas.

Cuando hablamos de ciudades modernas, al igual que Brasilia, existen otras ciudadescapitales planificadas y construidas en su totalidad, y de no tan antigua edificación, como Islamabad en Pakistán, Canberra en Australia, Abuya en Nigeria, Putrajaya en Malasia y Naipyidó en Birmania; en tanto, cuando hablamos de ciudades históricas que han venido experimentando procesos de pauperización, reconstrucción y modernización, encontramos ejemplos notables de ello, en capitales latinoamericanas como Ciudad de México, Buenos Aires, Lima o Río de Janeiro, complejos urbanos en cuyos centros históricos prevaleció el modelo racionalizado y regular en forma de damero cuadricular, con calles cortadas en línea recta, delimitando una serie de manzanas rectangulares. Diseño romano, románico o neolatino, traído por los españoles tras la conquista de América -seguido también por los portugueses-, cuya distribución cuadricular permitía una mejor orientación, sobre todo si la comparamos con el esquema de algunas antiguas ciudades europeas, cuyo trazado, de herencia medieval, la conformaban o siguen conformando, calles irregulares y manzanas trapezoidales, donde, en algunos casos, algún edificio importante, como una catedral o un palacio, era el elemento primordial alrededor del cual se fueron trazando avenidas y ubicaron grupos residenciales.

\section{Ciudades históricas y estéticas}

En la historia, las ciudades se han instituido como centro de poder político, económico, cultural y militar de las civilizaciones, en una larga marcha evolutiva que ha ido desde las antiguas nociones de ciudades-Estado griegas, hacia la de Estados-nacionales modernos.
Algo que en Occidente alcanzó a consolidarse recién en el siglo XVII, con el advenimiento del Estado-nación, a partir del acuerdo de Westfalia, de 1648, tratado que significó el fin de la Guerra de los Treinta años y el origen de un proyecto sociopolítico nacional único y uniformizante, en la figura del moderno Estado-nación; pero que a la vez se convirtió en represor de aquella tendencia natural hacia la diversidad cultural, producida por aquella multiplicidad antropológica desplegada en las inmensas extensiones geográficas que comprenden los Estados-nacionales.

En la ciudad, las diferentes escuelas constructivas suelen sucederse hasta brindarnos, cada una de ellas, su particular poética, extendiendo sus equivalencias estéticas hacia otras artes, como con el gótico, desplazado luego por el renacentista, a su vez reemplazado por el barroco, y seguido por el neoclásico, hasta experimentar, en pleno siglo XX y XXI, una profusión de vanguardias arquitectónicas, simultáneas y sucesivas, sustentadas en aplicaciones eminentemente funcionales, que han derivado en la construcción de viviendas, edificios y conjuntos habitacionales. En este sentido, cualquier modificación en la orientación del conocimiento ha implicado una transformación de las tipologías urbanas. Por lo que, la arquitectura, como disciplina y manifestación estética, como el arte de construir y decorar conforme a reglas determinadas, es también el reflejo del pensamiento y vivencias de una época, un período que va resignificando los patrones de diseño y construcción de edificios y viviendas que constituirán la imagen visible de la ciudad.

Así, en la historia se han dado una serie de sustituciones, fusiones y confrontación de tendencias constructivas, que, según la fuerza con la que eclosiona una forma de hacer arquitectura y de construir la ciudad hasta hacerse hegemónica, va difundiéndose hasta saturarse y perder el interés de sus seguidores y probables gestores. Algo que fue actuando y alterando también en los modelos de referencia preexistentes en las estructuras urbanas. A partir de proyectos de modernización sustentados en la intervención de áreas centrales y colaterales, 
en muchos casos determinados por su forma cuadricular, para poder abrir y superponer un sistema de avenidas diagonales $\mathrm{u}$ oblicuas, $\mathrm{y}$ paralelas sobrepuestas al tejido tradicional de la ciudad, para dar paso a mallas romboidales y superpuestas al trazado en forma de damero original, con el fin de descomprimir el área central de la ciudad, y generar situaciones espaciales irregulares, a partir de la introducción de vías diagonales convergentes y concéntricas, para vincular así, plazas, parques, encrucijadas y edificios públicos.

En este sentido, ante la complejidad alcanzada por las urbes contemporáneas a lo largo de la historia, podríamos asumir que son en sus líneas estructurales y su trazado donde residen las pautas para una clasificación más o menos estricta de la ciudad, y su ubicación en el interior del paradigma constructivo en el que esta fue concebida. Sobre todo si asumimos, que, por un lado, el factor socio-económico-cultural resulta fundamental para este análisis; mientras, por el otro, el factor teórico-técnico-histórico con el que se ha enfocado el estudio de los complejos metropolitanos resulta trascendental para un diagnóstico y la ubicación de la ciudad en la historia. Desde un estudio racionalizado que tiende a ocuparse del análisis de las estructuras y su distribución en las urbes, asumiendo el rol trascendental y referencial de estas, cabe preguntarse si se puede hablar de ciudades modernas, considerando zonas de alta densidad demográfica y actualidad arquitectónica cuyo diseño urbano fue concebido en el siglo XVII, lo que ha permitido esbozar clasificaciones historicistas de los complejos urbanos. Pues es en las estructuras urbanas de la ciudad, donde permanece latente el sello y la mentalidad de la época y el paradigma dentro del cual la ciudad fue edificada. Lo que ha hecho que, con el paso del tiempo, estas ya no respondan a las novísimas exigencias de la vida contemporánea.

Así, en términos urbanos, sería el diseño el que indicaría si estructuralmente una ciudad es moderna o antigua. Por lo que hablar de procesos de modernización nos puede dar algunas pautas para entender estos cambios urbanos a lo largo de la historia, producidos por la extensión y densificación de los espacios metropolitanos. De ahí que en las cartografías de las ciudades contemporáneas, aún coexistan sectores históricamente tradicionales y sectores modernizados que van reforzando la complejidad de la ciudad actual. Lo que nos dice que las ciudades contemporáneas son una confluencia de estructuras urbanas y arquitectónicas pertenecientes a diferentes períodos de evolución social y a diversos estilos constructivos. Por lo que cabe preguntarse también si se les debe llamar a París, Roma, Berlín, Pekín o New York, ciudades antiguas o ciudades modernas; y tendríamos que recurrir a discriminar los factores socioeconómicos-culturales-técnicos-históricos, que estas ciudades cobijan para dar una respuesta sensata; pues, no obstante que ninguna de estas ciudades corresponde al siglo XVIII y XX, en muchos sentidos se les suele conocer como sociedades modernas.

En este sentido, cabe mencionar lo que Saskia Sassen (1999) ha denominado ciudades globales, al estudiar y denominar de esta forma a New York, Londres y Tokio, ciudades que han desarrollado plazas de mercados mundiales, integradas o interconectadas tecnológicamente, que serían los nuevos centros de concentración económica y de control financiero, vía operaciones globales, con injerencia en la organización, administración y gestión de la economía mundial, ciudades a las que quizá también se podría agregar Berlín o París. O lo que Edward W. Soja (2008) ha llamado "postmetrópolis", para él relacionadas a una noción posmoderna de la ciudad, ciudades en las que convergen, al mismo tiempo, procesos de desterritorialización y reterritorialización social, dándose una suerte de fragmentación integradora, en la ciudad, porque a la vez que las realidades urbanas preexistentes van extendiéndose, se va debilitando la idea de territorialidad de las comunidades sociales; por lo que lo urbano se va integrando con lo no urbano, haciendo que los límites entre el interior y el exterior se vayan difuminando, y donde conceptos como "ciudad", "suburbio", "campo" y "metrópoli" van perdiendo sentido. 


\section{La ciudad como centro de esencialismos}

Las grandes ciudades son esencialmente ejes de las clases medias. Sus estructuras o trazado urbano, por lo general, han sido realizados en torno a una plaza principal, un templo $y$ un centro de control político-administrativo, modelo desde donde sus líneas de composición, como parámetros y núcleos de comprensión constructiva, tienden a extenderse, desde el centro hacia los márgenes. Esquema que tiende a repetirse $\mathrm{y} / \mathrm{o}$ a descender fractalmente -sobre todo si consideramos las ciudades medianas, las pequeñas, además de otros pueblos o asentamientos minúsculos interiores o alejados, que tratan de mantener una misma estructura, como principio administrativo o de autoridad- hacia otras escalas geográficopoblacionales, desde lo urbano hacia lo suburbano. En un entramado geopolítico asumido como redes de distribución de poder, que no solo tienen incidencias geográficas sino también histórico-territoriales, que pueden ir desde las parroquias, los municipios, condados, reinos, corregimientos, provincias, comarcas, departamentos, Estados, organizaciones pluriestatales, etcétera, entendidas como formas de delimitar el reparto o distribución geográfica del poder desde niveles macro hacia escalas microurbanas.

En este sentido, existe una suerte de reproducción "fractal" de modelos y jerarquías urbanas, que tiende a repetirse en sus múltiples niveles geopolíticos, como líneas de autoridad o estructuras de poder que se van repitiendo y manifestándose en un entramado que va de lo nacional hacia lo local, de lo metropolitano hacia lo suburbial, en un orden que ha ido determinando que en las grandes ciudades -las capitales de los distintos países- residan los poderes nacionales, en las medianas, los poderes provinciales y que en las pequeñas solo se ubique un control local. Y cuando esta escala se reduce bastante, puede ser común encontrar en las zonas distantes y alejadas de los diversos países, minúsculos poblados en medio de extensos ambientes rurales o desérticos, con las mencionadas características estructurales, hasta hallar lugares cuyo centro está dominado por un templo o iglesia y una minúscula plaza o un campo deportivo ${ }^{2}$.

La extensión o modelo cuadriculado o radial de la ciudad, según sea el caso, se complementa con otra forma de habitación o habilitación urbana de grupos o colectivos humanos, que fueron instalándose a lo largo del trecho de una autopista, bordeándola, teniendo como eje aglutinante y de crecimiento urbano a la carretera misma, hasta adquirir una disposición lineal que las va asemejando a la Ciudad lineal (1886), de Arturo Soria-Mata; pero, a diferencia de los proyectos de Soria-Mata o el proyecto de Roadtown (1910) de Edgar Chambless, que obedecían a un orden teórico de interconexión racional (Dupuy, 1998), estos poblados, que se van extendiendo aleatoriamente, vienen a ser espontáneas aglomeraciones, que obedecen más bien a una necesidad práctica, muchas veces comercial o únicamente como punto de enlace entre ciudades, desarrollándose sin mediar ningún plan urbanístico en su concreción, hasta integrar ciudades enteras en su interior.

\section{Funcionalismo y fragmentación}

Al hablar de la ciudad como lugar de referencia política, encontramos que la tradición germánica y latina nos ha dejado la acepción "burgo" para referirnos a poblaciones pequeñas dependientes de otra principal, vocablo del que se deriva el cargo burgomaestre referido al gobierno de las ciudades. En este sentido, las ciudades satélites son conjuntos urbanos que dependen de una ciudad central, desarrollados en los alrededores de una ciudad oficial, y a veces separados por grandes espacios sin urbanizar, luego circundados e integrados por el caótico crecimiento de los cinturones de pobreza o villas miseria ${ }^{3}$, que caracterizan a las principales ciudades del Tercer Mundo, determinando así su complicada y a veces colapsada geografía urbana.

\footnotetext{
Sobre todo asentamientos urbanos ligados a cierto tipo de protestantismo, que poseen un templo, como eje central y al costado un campo de basquetbol integrado a uno de fulbito.

3 De esto hay muchos ejemplos, desde los suburbios de África, Arabia hasta las favelas brasileñas, entre otros guetos miserables o "villas miseria" de América Latina y el mundo.
} 
La revolución industrial y el avance tecnológico ocasionaron cambios profundos en la constitución y configuración de las ciudades hasta entonces preindustriales y con un ritmo de desplazamiento lento, pues la aparición de tranvías y otros vehículos motorizados forzaron a la transformación de las calles hasta el momento planificadas solo para la circulación de peatones y vehículos halados por caballos, para convertirse en pistas y carreteras. Así, el crecimiento demográfico, la irrupción de las industrias y las grandes masas de obreros conmocionaron la ciudad, imponiéndole retos que los tradicionales arquitectos, estancados en el pasado debido a su esteticismo aristocrático, no podían resolver. Profundos cambios habían desencadenado obsolescencias en la concepción urbana e ineficacia en las construcciones habitacionales $e$ industriales, poco funcionales ante las novísimas exigencias que imponía el nuevo contexto. Problema que solo pudo ser resuelto por la acción e irrupción de los ingenieros, quienes, conocedores del hierro, del acero, del vidrio y el concreto armado, fueron acercando la tecnología al arte constructivo, abriendo nuevos caminos para la arquitectura contemporánea.

Una muestra de ello será el Palacio de cristal, construido por el constructor de hibernaderos Joseph Paxton, en 1851 y la celebérrima torre construida por el ingeniero Gustave Eiffel entre 1887 y 1889 . Lo que hizo que aquella célebre división escolástica que existía entre los arquitectos $e$ ingenieros, fuese disuelta $y$ saldada por la denominación "constructores" que fue incluyéndolos a ambos.

Las nuevas técnicas de construcción, las maquinarias, la gran variedad de materiales y elementos de los que disponen actualmente los constructores, fueron brindando posibilidades extraordinarias que produjeron también un cambio de mentalidad en el desarrollo y aplicación del urbanismo. Una corriente racionalista gestada en el período de entre guerras, que trataba de conciliar aquellas teorías funcionalistas, debidas a las novísimas necesidades pragmáticas y económicas del nuevo contexto industrial, con las tradicionales exigencias urbano-artísticas, cimentadas en las emociones colectivas de la sociedad. Un período en el que los sistemas constructivos empezaron también a renovarse, a partir de circuitos comprometidos con las artes, con Walter Groupius, Mies Van Der Rohe y Theo Van Doesburg, que destacaron desde renovadoras escuelas, como el neoplasticismo, la Bauhaus y el constructivismo ruso. Para posteriormente hablarse de movimientos constructivos no tan definidos, como los de arquitectura radical, arquitectura orgánica, ecléctica, cosmológica y posmoderna.

Con todo esto, la arquitectura funcional ${ }^{4}$, cuyo advenimiento había hecho que los muros fueran perdiendo su habitual protagonismo en las construcciones, hasta perder totalmente su cualidad de elemento sustentante para darle mayor importancia a las estructuras, modelo constructivo tendiente a la estandarización, en sus formas rígidas y geométricas, repetitivas y minimalistas, entrará en boga en las principales capitales del mundo, aplicándose también en importantes ciudades latinoamericanas como Bogotá, Buenos Aires, Lima, Santiago, Montevideo, además de otras, en las que, bajo estos preceptos, se construyeron edificios, unidades vecinales y ciudades satélites; proyectos habitacionales con los que se buscaba contrarrestar el desorden demográfico creando zonas de alta densidad poblacional, instaladas en infraestructuras superpuestas que ordenadamente permitían albergar, en múltiples departamentos, a una mayor cantidad de familias.

Todo esto hizo que la ciudad, hasta entonces unitaria, debido a la lenta evolución civilizatoria, vista como un todo orgánico labrado por el paso de los siglos y los diferentes registros artísticos que fueron otorgándole ese carácter distintivo y coherente que todavía se puede encontrar en algunos focos históricos de las antiguas urbes,

\footnotetext{
4 Las nuevas edificaciones le daban mayor importancia a las estructuras, que a manera de esqueleto o soportes de carga -armazones, pilares, vigas de acero y hormigón armado- hacían que las paredes sean elementos que podían ser prescindibles, además de permitir construcciones colosales e insólitas, aunque carentes de la retorcida belleza de las construcciones clásicas.
} 
se vea fragmentada. Haciéndose heterogénea debido a la expansión de los asentamientos industriales, a la exacerbación de las diferencias sociales y a la pobreza que tiende a ocupar las periferias urbanas. Lo que, ante las distancias producidas por la sobreextensión urbana, y la evolución del transporte, produjo la necesidad de construir carreteras que fueron haciendo pedazos a la antigua configuración de la ciudad.

\section{Pauperización y gentrificación}

Las metrópolis modernas tienden a desarrollarse verticalmente debido al incremento demográfico de su burguesía que suele ubicarse en edificios colosales y modernos, edificios presentados como una solución a la falta de espacio para viviendas unifamiliares en la ciudad. En tanto, los complejos urbanos pauperizados y periféricos de las zonas "marginales", ante su densificación, se expanden horizontalmente, vía construcciones no planificadas, improvisadas, antifuncionales y -en el mejor de los casos- de una estética comunitaria transportada desde el campo hacia la ciudad, por sus nuevos pobladores migrantes, cuando se trata de habilitar y habitar los márgenes; migrantes que suelen hacerse cargo de construir ciudades nuevas en las periferias urbanas, o rehabitar las tradicionales ciudades colapsadas, y abandonadas por las clases medias altas y altas, tras la crisis espacial que los obligó a migrar de los antiguos ejes históricos pauperizados.

En este sentido, para el reordenamiento y planificación urbano-demográfica, la solución del espacio y de la vida urbana opone un proceso de densificación intraurbana, que ocasionaría un mayor crecimiento vertical de las ciudades, lo cual concentraría más los flujos económicos y sociales, nucleando a sus habitantes; frente a uno de expansión urbana, que al extender la ciudad horizontalmente, está ocasionando el desborde de sus periferias, extendiendo la ciudad y desconcentrando, con ello, sus flujos económicos, demográficos y sociales, ocasionando pérdidas en términos de tiempo y dinero, debido a las distancias a recorrer al movilizarse desde un punto hacia otro, y a un ineficaz o colapsado sistema de transportes que cubren las ciudades populosas.

De ahí que también se está dando otro proceso, pero para nada espontáneo, debido a las motivaciones económico-inmobiliarias que las están cifrando en la mayoría de capitales y ciudades importantes del mundo, como París, Londres, Amsterdam, Nueva York, Barcelona, además de las distintas ciudades importantes de América Latina; en lo que la británica Ruth Glass, hacia 1964, ha denominado gentrificación, como un proceso que implica la llegada de nuevos habitantes de clase media alta, a barrios populares antiguos y deteriorados, del centro de la ciudad, transformando el hábitat y elevando el nivel de vida, vía la reconfiguración del espacio público y de los comercios, a través de políticas culturales que la propician, lo que produce la renovación y revaloración de estos centros urbanos -anteriormente depreciados debido a la desatención de las autoridades-, produciendo el desplazamiento o migración inversa de las clases más humildes, que no pudieron hacer frente a este proceso de aburguesamiento inmobiliario ${ }^{5}$. Es lo que para algunos representa la recuperación de los espacios históricos y/o tradicionales y su puesta en valor, mientras para otros esto implica la "segregación" de sus habitantes pobres, que tienden a perder sus viviendas.

\section{Representación final}

El inconcluso debate entre modernidad $y$ posmodernidad, ha dejado un amargo sabor de imprecisión generalizada. Pues a los primeros textos de Jean-François Lyotard (1990) y de Jurgen Habermas (1988), polémicos entre sí, le han seguido múltiples lecturas que

\footnotetext{
Neil Smith ha definido esto de la siguiente manera: "La gentrificación es el proceso por el que los barrios pobres y proletarios, ubicados en el centro de la ciudad, reformados a partir de la entrada del capital privado y de compradores de viviendas $e$ inquilinos de clase media - barrios que previamente habían sufrido una falta de inversión y el éxodo de la propia clase media-. Los barrios más humildes de clase trabajadora están en proceso de reconstrucción; el capital y la alta burguesía están volviendo a casa, y para algunos de los que se encuentran a su paso, no se trata precisamente de algo agradable" $(2012,74)$.
} 
han ido esbozando intentos de elucidación conceptual en pos de desentrañar la esencia de los cambios contemporáneos, ensayándose rótulos como segunda modernidad (Beck 2000), sobremodernidad (Augé, 1993), transmodernidad (Dussel, 2005), modernidad líquida (Bauman, 1999) o hipermodernidad (Lipovetsky, 2006). Aquí, llámesele como quiera, eso no tiene mucha importancia. Los cambios impuestos por el fin de la modernidad han difundido mucho la palabra crisis, crisis que parece reproducirse $y$ diseminarse en todas las esferas de la sociedad, afectando incluso los espacios cotidianos de la vida privada. Manifestándose no solo como una moda intelectual negativa, sino como un conjunto de sintomatologías generalizadas de las que ni siquiera la ciudad, como sistema de interrelaciones sociales, ha podido escapar.

Hasta ahora, la ciudad había venido siendo un gran centro territorial de concentración de individuos, un foco de desarrollo cuya función básica -en cercanía- era facilitar la mayor cantidad de comunicación posible, el mayor flujo de información, intercambio comercial, aprovechamiento efectivo de los recursos locales, circulación y desplazamientos a un costo mínimo en términos de tiempo y dinero. Pero con la globalización y los avances tecnológicos, que han ido reduciendo las distancias, brindando nuevas posibilidades de asociación y disociación social, las nociones clásicas que definían a los complejos urbanos como un todo orgánico están cambiando; y la esencia que produjo a las grandes ciudades está siendo violentada.

Entonces, ante esta tendencia hacia la desaglomeración territorial en las sociedades más desarrolladas y tecnologizadas del planeta, los complejos urbanos marcharían hacia una dispersión, disgregación o desaparición por baja densidad; mientras, de manera inversa, en los países del Tercer Mundo, América Latina entre ellos, las zonas urbanas distantes crecen hasta unificarse con los centros, con una población que aumenta con gran rapidez, producto de los desplazamientos debidos a la pobreza y exclusión rural, condenando a las ciudades hacia el colapso, en este orden global de desigualdades. De allí que se puede asumir que la ciudad sigue siendo el lugar de la utopía, pero de una utopía que está aún por rediseñar. 


\section{REFERENCIAS}

Anderson, Benedict (1993) Comunidades imaginadas. Buenos Aires: Fondo de Cultura Económica.

Appadurai, Arjun (2001) La modernidad desbocada. Buenos Aires: Fondo de Cultura Económica.

Auge, Marc (1993) Los "no lugares": espacios del anonimato. Una antropología de la sobremodernidad. Barcelona: Gedisa.

Bauman, Zygmunt (1999) Modernidad líquida. Buenos Aires: Fondo de Cultura Económica.

Beck, Ulrich (2000) Un nuevo mundo feliz. La precariedad del trabajo en la era de la globalización. Barcelona: Paidós.

Dupuy, Gabriel (1998) Urbanismo de las redes. Teorías y métodos. Barcelona: Oikos-Tau.

Dussel, Enrique (2005) Transmodernidad e Interculturalidad: Interpretación desde la Filosofía de la Liberación. En Lander, Edgar (comp.) La colonialidad del saber: Eurocentrismo y ciencias sociales. Perspectivas latinoamericanas. Buenos Aires: Unesco, Ciccus, Clacso.

Habermas, Jürgen (1988) La modernidad, un proyecto incompleto, en Foster, Hal (ed.) La posmodernidad. México, Editorial Kairós.

Klein, Naomi (2002) Nologo. El poder de las marcas. Barcelona: Paidos.

LACLAU, Ernesto; MOUFFE, Chantal. (1987) Hegemonía y estrategia socialista. Hacia una radicalización de la democracia. Madrid: Siglo XXI.

Le Corbusier [1943] (1999) Principios de urbanismo. (La Carta de Atenas). Barcelona: Ariel.

Lipovetsky, Gilles; Sebastien, Charles (2006) Los tiempos hipermodernos. Barcelona: Anagrama.

Lyotard, Jean François (1990) La condición posmoderna, México: REI.

Observatorio Metropolitano de Madrid (ed.) (2015) El mercado contra la ciudad. Sobre globalización, gentrificación y politicas urbanas. Madrid: Traficante de sueños.

Ojeda, Rafael (2011) Ciudades fracturadas, en revista Quehacer N. ${ }^{\circ}$ 184. Lima, 2011. pp. 60-67.

Ojeda, Rafael (2015) Miradas sobre el espacio urbano. La ciudad como centro de esencialismos en crisis, en revista Campo Letrado, año 4, № 5. Lima, 2015. pp. 52-64.

Ojeda, Rafael (2016) Síntomas limeños: Heterotopias, desfases y riesgos de la capital peruana, en revista Concensus, N. ${ }^{\circ}$ 2. Volumen 21. Lima, julio-diciembre 2016. pp. 71-83.

Rodríguez Magda, Rosa María (1989) Hacia una teoría transmoderna. Barcelona: Anthropos.

Sassen, Saskia (1999) La ciudad global. Nueva York, Londres, Tokio. Buenos Aires: Editorial EUDEBA.

Servier, Jean (1969) Historia de la utopía. Caracas: Monte Ávila editores.

Smith, Neil (2012) La nueva frontera urbana. Ciudad revanchista y gentrificación. Madrid: Traficante de sueños. 
Soja, Edward W. (2008) Postmetrópolis. Estudios críticos sobre las ciudades y las regiones. Madrid: Traficantes de sueños.

Venturi, Robert; Scott Brown, Denise (1971) Aprendiendo de todas las cosas. Barcelona: Editorial Tusquets.

Venturi, Robert, et al. Denise (2000) Aprendiendo de Las Vegas. El simbolismo olvidado de la forma arquitectónica. Barcelona: Gustavo Gili S.A.

Von Eckardt, W. (1982) Live the good life. American Council for the Arts.

Fecha de recepción: 15-08-17

Fecha de aceptación: 20-09-17 